\title{
TRANSLATION OF “SIR ORFEO” INTO SPANISH
}

\author{
José Antonio Alonso Navarro \\ Professor of Modern Languages and Humanities, Norte University (Asuncion, Paraguay) \\ e-mail: meildeja@yahoo.com
}

Resumen. Presentamos aquí una traducción al español del poema medieval inglés "El caballero Orfeo" compuesto a ha sido darla a conocer al público moderno de habla hispana por su belleza literaria y su historia, una historia que, ciertamente, no es original. Sin embargo, sí lo es la manera en la que su autor ha sabido adaptar el mito griego clásico a la mentalidad medieval inglesa de los lectores u oyentes del momento con el objeto de granjearse su interés, así como entretenerlos y enseñarlos con un propósito didáctico. El poema posee todos los elementos propios de un lay prototípico: un caballero-rey, una historia de amor, una búsqueda física y espiritual, el mundo sobrenatural (o tierra de las hadas) y valores morales y espirituales que deberían ser tenidos en cuenta por la audiencia. La traducción al español del "Caballero Orfeo" ha tratado de ser lo más fiel posible al poema inglés original para que no pierda ni su esencia, ni su frescura, ni su carácter literario. "El caballero Orfeo" fue un poema muy popular en su época, y no hay duda de que volverá a serlo en el siglo XXI a la luz de ópticas y perspectivas diferentes.

Dalabras claves: “El caballero Orfeo”, Orfeo, lay, mitología griega, mitología celta, Otro Mundo. 


\section{ntroduction to the Medieval English poem
"Sir Orfeo"}

In the introduction written by the editors Anne Laskaya and Eve Salisbury for the digital version of "Sir Orfeo" [Laskaya, Salisbury], we may read that the earliest known Middle English version of this English poem is preserved in the Auchinleck manuscript (also called Advocates), which dates from about 1330-1340. In addition, we are told that it was written for affluent readers who did not belong, however, to the aristocracy. As to its authorship, we do not know who wrote "Sir Orfeo", but in view of its linguistic features we do know by the above-mentioned editors that it was composed in the late $13^{\text {th }}$ or early $14^{\text {th }}$ centuries within the Westminster-Middlesex area. Its earliest source might have been a text written in old French. There are references to a musical lay about Orfeo in several old French texts. Laskaya and Salisbury do mention the $12^{\text {th }}$ century romance "Floire et Blanceflor" ("le lai d'Orphey", line 855), the "Lai de l'Espine" ("Le lai lor sone d'Orphei", line 181), and the Vulgate "Prose Lancelot" ("lay d'orfay"). It is not difficult to associate the name of Orfeo with the classical Greek myth of Orpheus, a myth which will be readapted in the medieval English poem by introducing elements from the Celtic and Germanic mythology and folklore related to the Fairyland or Otherworld from Breton lays composed by old French writers, such as Marie de France who lived in the $12^{\text {th }}$ century.

"Sir Orfeo" is framed within the Breton lays composed in Middle English in the $13^{\text {th }}$ and $14^{\text {th }}$ centuries. They form part of the English and French medieval romances. They are generally made up of 600-1000 lines, and recount love and knight-related stories comprising recurring Celtic motifs associated with the Fairyland and the supernatural world (or Otherworld). The word lay or lai might come from the Irish term laid (song), as suggested by Zipes [Zipes: 62]. This author, moreover, points out that the Arthurian legends might have settled down in Brittany from Wales, Cornwall and Ireland during the $9^{\text {th }}$ century or perhaps, a little bit earlier, and that lays related to courtly love and (Arthurian) knights might have initially expanded on the continent (Brittany as the starting point) as songs throughout minstrels and harpers.

The earliest recorded lay seems to be that of Robert Biket ("Lai du cor"), which dates from mid to late $12^{\text {th }}$ century. Robert Biket was an Anglo-Norman writer who lived between the $12^{\text {th }}$ and $13^{\text {th }}$ centuries. He composed his "Lai du cor" in England about 1170-1180 as a satire or parody against the knightly ideals of the Arthurian cycle. The lay relates the story of a horn which refuses to serve wine to cuckold or cheated husbands. It is a rather brief poem which contains less than 600 lines composed in Anglo-Norman. From the $12^{\text {th }}$ century onwards, Breton lays began to develop as a literary genre with the spur of Marie de France, who composed 12 lays in all about 1170. Marie de France lived in England during the reign of Henry II between the $12^{\text {th }}$ and $13^{\text {th }}$ centuries, respectively. Marie 
de France's lays could be based upon Breton lays sung by Breton minstrels during the $9^{\text {th }}$ century, those of which have not been preserved. In addition to her, several English authors composed lays in England during the $13^{\text {th }}$ and $14^{\text {th }}$ centuries, perhaps, one of the most popular ones was Thomas Chestre.

Marie de France composed her lays in octosyllables based upon the concept of courtly love and the adventures of knights. They can be read in the Harley 978 manuscript, a $13^{\text {th }}$ century manuscript preserved at the British Library. The Harley manuscript comprises a 56-line prologue in which the Anglo-Norman author expounds that the motivation that prompted her to write the lays was to follow the example of the ancient Greeks and Romans, and thus, she decided to write stories that were amusing, didactic, and morally exemplary, and, in turn, to preserve them in the future. This is the list of lays contained in the Harley 978 manuscript: "Guigemar", "Equitan", "Le Fresne", "Bisclavret", "Lanval", "Les Deux Amants", "Yonec", "Laüstic", "Milun", "Chaitivel", "Chevrefoil", and "Eliduc". On the other hand, amongst the most popular Breton lays in Middle English, we may highlight: "Sir Orfeo", "Sir Degaré, "Sir Gowther", "Emaré, "Sir Launfal" and "The Erle of Toulouse". Geoffrey Chaucer wrote one lay titled "The Franklin's Tale", which may be found in the "Canterbury Tales".

In the Greek myth, Orpheus, who was the son of Apollo and Calliope, went down into the underworld in order to retrieve his wife Eurydice when she was bitten by a serpent (or a group of vipers) when fleeing from Aristaeus (in the source of Virgil. Other sources refer to a satyr). During his trip (or catabasis / katabasis) to the underworld, Orpheus had to confront many perils, but he used the power of his music to go through all of them successfully until he arrived at the place where both Hades and Persephone were. The two of them, moved by Orpheus's attitude, allowed him to take his wife back to him to the surface of the world, but on condition that he walked in front of her, and did not turn back until they both had come out of the underworld and the sunbeams had already bathed the woman. However, when Eurydice was about to step into the upper world, Orpheus, who could not resist his desire to look at his wife, turned back and she vanished into the air forever.

In the medieval English poem, the story does not take place in Ancient or classical Greece, but in England. Eurydice, who is referred to in the text as Heurodis, does not perish, but she is abducted by the king of Fairyland when she is in a garden sleeping under a tree. When this happens, Orfeo, king of a medieval English realm, commissions his loyal steward to rule in his place, and gives instructions so that a new Parliament is chosen and a new king is crowned if he dies. Afterwards, after abandoning his kingdom and wealth, Orfeo dons on his pilgrimage cloak, takes his harp, and goes into exile. After 10 years wandering, sleeping outdoors, and feeding on berries and fruits in 
summer and roots and tree bark in winter, one day he finds out Heurodis riding with a group of ladies who are hawking by a river. Then, he decides to follow them to a rock that leads into the otherworld. The otherworld is described as a countryside upon which is set a marvelous castle made of gold and glass. The guard of the castle lets him in, and inside Orfeo witnesses people that were thought to be dead, but actually, they were not. Amongst those people he finds his wife Heurodis, who is sleeping. The fairy king rebukes Orfeo for having trespassed the castle without having been summoned up either by him or by any member of his retinue. Then, Orfeo attempts to please him and his queen by playing the harp. They both enjoy Orfeo's pleasant music (minstrelsy) very much, and the king asks Orfeo to request something he likes. Orfeo asks for Heurodis, and the king, despite some initial reservation, allows Orfeo to take Heurodis back to England.

On his arrival in Winchester, Orfeo's city, Orfeo leaves Heurodis in a beggar's cottage, and heads for his castle disguised as a beggar who plays the harp in order to test his steward's loyalty. His steward, who has not recognized his lord, allows his entrance in the castle to play the harp. Once he has finished playing, his steward notices the king's harp, and asks him how and where he got it. Orfeo relates that he found the harp about ten years ago close to the mutilated body of a man who had been devoured by lions and wolves. After hearing this, the steward shows grief and swoons. It is then that Orfeo finds that his steward really loves him, and reveals to all his subjects that he is Orfeo. Next, the steward is appointed Orfeo's heir and Heurodis is brought back to the castle. The poem concludes with the announcement that the steward is crowned and becomes a king after Orfeo and Heurodis have had a long life together.

In the Celtic mythology, the Otherworld is usually described as a supernatural realm in which eternal youth, beauty, health, joy, and wealth prevail. However, this supernatural setting is only targeted at few people. This is the case of some Irish heroes, such as Cúchulainn, Fionn mac Cumhaill, or Bran mac Febal, who managed to gain access to it in different ways. This Otherworld can be found on an island, underground, under the water, or across the sea. In some cases, its access is also possible through a cave, a rock, or an ancient burial mound. In the Welsh mythology, the Otherworld is called Annwyn or Annwfn, and in the Irish mythology it is called Tír na nÓg, Tech Duinn, Emain Ablach, Tír nAill, Tír Tairngire, Tír fo Thuinn, Tír na mBeo, Mag Findargat, Mag Argatnél, Mag Ildathach, Mag Cíuin, Tír na mBan or The Isle of Ladies / Women, The Paradise of Birds, Mag Mell (Magh Meall) or The Island of Joy.

"Sir Orfeo" is preserved in three manuscripts. The earliest one, as we said above, is the Aunchinleck manuscript from about 1330 (also called Advocates 19.2.1); the second one is the Harley 3810, which dates from the 15 th century; 
and the third one is the Ashmole 61, whose version of "Sir Orfeo" dates from about 1488. "Sir Orfeo" is rooted in the tradition of the Breton lays written in Old French spurred and composed by Marie de France. One of the literary works that might have had a possible influence upon the medieval English poem is "The Wooing of Etain". Étaín is a very beautiful woman who comes from the Irish mythology. She is depicted as woman with golden hair, blue eyes, white skin and

\section{ПРИЛОЖЕНИЕ}

\section{Traducción en prosa del "Caballero Orfeo"} por José Antonio Alonso Navarro (versión digital de Laskaya, A. y Salisbury, E.)

Con frecuencia leemos y hallamos escrito, y esto es algo que saben bien los eruditos, que los layes cantados versan sobre hechos portentosos. Algunos refieren gestas en el campo de batalla y otros, historias tristes; otros, historias alegres y de regocijo; y otros, cuentan historias de traición, de engaño o de aventuras que acontecieron en el pasado; otros, en cambio, contienen historias festivas e historias obscenas; sin embargo, son muchas las historias que hay en ellos sobre el mundo de las hadas. Mas, en verdad, la mayoría de las historias que se cuentan en ellos son de tema amoroso. Los primeros layes acerca de aventuras que acontecieron en el pasado fueron compuestos por bretones en Bretaña.

Cuando los reyes escuchaban en cualquier lugar acerca de sucesos asombrosos que habían reddish eye-brows. In addition, she is king Ailill's daughter and the wife of a supernatural being. Finally, it is also possible to gain access to George Shuffelton's digital version of "Sir Orfeo" through the TEAMS Middle English Texts homepage. In addition, professor Shuffelton's printed version of "Sir Orfeo" is available in his 2008 book "Codex Ashmole 61. A Compilation of Popular Middle English Verse".

sucedido, tomaban con regocijo el arpa cual trovador y componían un lay, poniéndole después un título al terminar. Bien, de tales aventuras acaecidas en el pasado, aunque no puedo contarlas todas, sí podré contar, al menos, alguna que otra. De modo que, mis leales señores, disponeos a escuchar ahora la historia del "caballero Orfeo", quien, por encima de todo, amaba la música alegre que brotaba del arpa. Y no había duda de que cualquiera que se preciara de ser un buen arpista se sentía muy honrado con su presencia. Sin ayuda de nadie, tras poner en ello todo su ingenio y destreza, aprendió a tocar el arpa. Y tan bien aprendió a tocarlo, que no hubo en ningún lugar nadie mejor que él. En verdad, no había nadie en el mundo que, tras sentarse junto a Orfeo para escucharlo tocar el arpa, no pensara que se encontraba en el mismo Paraíso, tal era la melodía que salía de ella.

Orfeo era un rey y un alto señor en Inglaterra, además de un hombre robusto y valiente, generoso y cortés. Su padre descendía del rey 
Plutón y su madre de la reina Juno', los cuales, antaño, fueron tomados por dioses debido a las hazañas en las que ambos habían participado y a las gestas que habían contado. Este rey vivía en Tracia, ciudad de grandes fortificaciones. $\mathrm{Y}$ es que Winchester se llamaba entonces Tracia, sin duda alguna. El rey estaba casado con la dama Eurídice, que era una reina de virtudes excelsas $\mathrm{y}$, sin duda alguna, la dama más hermosa que pudiera caminar sobre la tierra, de una belleza tal que difícilmente se podría describir en su justa medida y, además, llena de amor y de bondad como ninguna otra. Ocurrió entonces a comienzos de mayo, cuando se asoma el buen tiempo y lejos quedan ya las lluvias invernales, y los campos se revisten de flores y los brotes de flor resplandecientes crecen sin rubor en cada rama de árbol con gran júbilo, que esta reina, la dama Eurídice, a última hora de la mañana, se llevó consigo a dos doncellas virtuosas con el fin de recrearse animadamente cerca de un jardín, ver brotar y expandirse las flores de aquí para allá, y escuchar a las aves trinar.

Las tres se sentaron debajo de un lindo manzano y en seguida, esta hermosa reina se quedó dormida encima de la hierba. Las doncellas no se atrevieron a despertarla, sino que la dejaron yacer allí y descansar plácidamente. De modo que estuvo durmiendo hasta pasado el mediodía y, al despertarse, comenzó a proferir gritos espantosos como si se hubiera vuelto loca. Se frotó las manos y los pies y se arañó el rostro hasta que comenzó a sangrar abundantemente. Hizo jirones sus vestiduras y pareció perder el juicio por completo. Las dos doncellas que la acompañaban ya no se atrevieron a quedarse con ella, así que sin dilación corrieron hacia el palacio para hacer saber a escuderos y caballeros que su reina se había vuelto loca, y pedirles que fuesen donde estaba ella y se hicieran cargo de la misma. Caballeros y también damas, y más de sesenta damiselas, se fueron a toda prisa al jardín donde estaba la reina. La tomaron en brazos, la llevaron finalmente a la cama, y allí la sujetaron con fuerza, mas, sin dejar de gritar, trató de salir de la cama. Cuando Orfeo escuchó lo ocurrido, se sintió más afligido que nunca. Se dirigió hasta el aposento de la reina con diez caballeros y ante ella se apostó. La miró y dijo con mucha pena:

- Oh, vida mía, ¿qué os sucede que habéis perdido la compostura que siempre guardasteis $\mathrm{y}$, sin causa aparente, os habéis puesto a gritar de tal manera que espanto ha causado? Vuestro cuerpo, que era de un blanco tan refinado, habéis destrozado con vuestras uñas. ¡Ay! Vuestro rostro, lozano como era, está lívido ahora como si estuvieseis muerta. Y vuestros delicados dedos, miradlos, han perdido todo color y están

\footnotetext{
${ }^{1}$ El autor menciona a Juno como "rey", pero, en realidad, Juno era la diosa romana del matrimonio y la maternidad. Juno era la hija de Saturno y de Ops y hermana y esposa de Júpiter, con el que tuvo dos hijos, Marte y Vulcano y una hija, Lucina.
} 
cubiertos de sangre. ¡Ay! Vuestros encantadores ojos lanzan una mirada torva como la que se lanza al enemigo. ¡Ay, señora! Os lo suplico, por compasión, no gritéis más de manera tan lastimera, y decidme qué os perturba y cómo puedo ayudaros.

Entonces, la dama, al fin, se calmó y se puso a llorar desconsoladamente mientras le decía al rey de esta manera:

- ¡Ay, mi señor Orfeo! Desde que nos conocimos, no nos hemos enfadado ni una sola vez, mas, muy al contrario, yo siempre os he amado con todo mi ser, como vos a mí. Sin embargo, ahora hemos de separarnos. Cuidaos mucho, pues debo marcharme.

- ¡Ay!, dijo el caballero, - ¡estoy perdido irremediablemente! ¿Adónde os vais a ir $\mathrm{y}$ con quién? Adonde vayáis vos, yo habré de acompañaros, y adonde vaya yo, vos habréis de acompañarme a mí.

- ¡No, no, señor! ¡No puede ser! Os diré por qué. Esta mañana, mientras dormía bajo nuestro jardín, se aproximaron a mí dos apuestos caballeros bien pertrechados con todas sus armas, y me pidieron que me dispusiera en seguida a hablar con su señor el rey. A lo que respondí con palabras un tanto osadas, pues ni me atreví a ello ni quise hacerlo. Viendo mi actitud, los caballeros se marcharon tan rápidamente como pudieron. Entonces, llegó su rey tan raudo y veloz como pudo con más de cien caballeros y cien damiselas, todos ellos montados en corceles tan blancos como la nieve y ataviados con atuendos tan blancos como la leche. Jamás había visto antes criaturas tan hermosas. El rey tenía en la cabeza una corona que no era ni de plata ni de oro rojo, sino de algún tipo de piedra preciosa que resplandecía con tanta intensidad como el sol.

Y tan pronto como se acercó a mí, tanto si quise como si no, me hizo cabalgar a su lado en un palafrén hasta conducirme a su palacio, el cual estaba suntuosamente decorado. Allí me mostró castillos y torres, ríos, bosques con flores y cada uno de sus majestuosos corceles. Después, me trajo de vuelta a nuestro jardín, y antes de marcharse me dijo de este modo:

- Señora, aseguraos de estar mañana aquí mismo bajo este manzano, pues os llevaremos a vivir con nosotros para siempre. Y si nos ponéis alguna traba a esto, no importa donde os halléis, iremos a por vos, y os descuartizaremos de tal manera que nada ni nadie podrá socorreros. $\mathrm{Y}$ aunque halláis sido descuartizada en mil pedazos, aun así, os llevaremos con nosotros.

Cuando el rey Orfeo escuchó esto dijo:

- ¡Ay, Dios mío! ¡Ay, ay! Más querría yo perder la propia vida que perder a mi esposa, la reina.

Después, pidió consejo a cuantos hombres pudo, pero sin que ninguno de ellos pudiera hacer nada. Al día siguiente, llegado el mediodía, cuando Orfeo ya había tomado sus armas y reunido a mil soldados bien pertrechados tan aguerridos como feroces, se encaminó con la reina hasta el manzano del jardín. Entonces, los soldados formaron dos hileras y se dispusieron a 
cada lado del lugar diciendo que allí se quedarían y morirían antes que permitir que se llevasen a la reina. Sin embargo, en medio de ellos, en un abrir y cerrar de ojos la reina fue arrebatada por arte de magia y encantamiento. Los hombres jamás supieron adónde se fue. A partir de entonces, el corazón de todos se turbó y se llenó de pena y de dolor. El rey se encerró en su aposento y varias veces cayó al suelo desmayado. Fueron tan grandes sus lamentos y gemidos que a punto estuvo de perder la vida sin remedio. Mandó llamar a sus barones, condes y grandes señores, y cuando estuvieron todos reunidos les dijo:

- Señores, delante de todos vosotros dispongo que mi mayordomo real gobierne mi reino a partir de ahora. Él ocupará mi lugar y se encargará de administrar mis tierras hasta donde alcancen. He perdido a mi reina, la dama más hermosa sobre la faz de la tierra, de modo que en adelante jamás veré a otra mujer. Me adentraré en lo más desolado y salvaje del bosque sombrío, y allí moraré para siempre en compañía de las bestias silvestres, y cuando os llegue la noticia de mi muerte, formad un parlamento y elegid un nuevo rey. Ahora ocuparos de todos mis asuntos como corresponde.

Al terminar de hablar el rey, grandes y chicos prorrumpieron en grandes sollozos en el salón, $\mathrm{y}$ nadie pudo proferir ya palabra alguna. Al unísono todos juntos se pusieron de hinojos y le rogaron que no les abandonasen. dicho.

- ¡Basta!, dijo el rey, - se hará cómo os he

Al abandonar su reino por completo, solo se llevó consigo un manto de peregrino. No quiso llevarse ni túnica ni caperuza, ni camisa ni tampoco bienes de ninguna clase. Lo único de lo que no quiso desprenderse bajo ninguna circunstancia fue de su arpa, y con ella caminó descalzo por las calles, sin que nadie quisiera acompañarlo. ¡Ay, Dios mío! Cuántas lágrimas de dolor por él se derramaron, él que había sido todo un rey coronado, y ahora se marchaba de la ciudad como un mendigo. Y después de atravesar el bosque caminando sobre matorrales, Orfeo ${ }^{1}$ se interna en la parte más desolada y salvaje del mismo. Nada de lo que halla lo consuela, sino que vive constantemente presa de una gran aflicción. Él, que había llevado puesta la piel abigarrada y de color gris, y en el lecho había dormido encima de ropas de cama de color púrpura, ahora yace sobre ásperos matorrales, cubriéndose con hojas y hierba. Él, que había sido dueño de castillos y torres, de ríos y bosques con flores, ahora, se ponga a nevar o venga una helada, este rey no tiene más remedio que hacer su cama en el musgo. Él, que había tenido damas y caballeros de gran valía postrándose de hinojos ante él, no

\footnotetext{
${ }^{1}$ Ahora el autor-narrador pasa del tiempo verbal en pasado al tiempo presente, que resulta más “visual” para una audiencia que esté escuchando el poema.
} 
ve ahora nada que lo agrade, excepto sierpes que se arrastran junto a él. Él, que había tenido en abundancia los manjares y las bebidas más exquisitos, ahora tiene que cavar y escarbar en busca de las raíces que necesita para sobrevivir. En verano se alimenta de frutos silvestres y de bayas de poco valor.

En invierno no encuentra nada para comer excepto raíces, hierba y corteza. Tantos rigores y penurias hicieron finalmente mella en su cuerpo, ahora consumido y agrietado. ¡Ay, Señor! ¿Quién puede narrar los padecimientos que tuvo que soportar este rey durante más de diez años? Tanto le creció la barba negra y áspera, que hasta la cintura le llegó. Y en cuanto a su arpa, que era lo que más feliz le hacía, este la escondió en el hueco de un árbol, mas cuando el tiempo estuvo despejado y soleado, Orfeo la cogió en seguida para consolarse y comenzó a tocarla a voluntad. $\mathrm{Y}$ en el instante en el que la música empezó a resonar por todo el bosque, todas las bestias salvajes que allí se hallaban se reunieron para deleite suyo en torno a él, y todas las aves que en el bosque estaban, se acercaron y se posaron en una zarza para escucharlo tocar con gran maestría. ¡Qué hermosa melodía brotó de ella! Y cuando dejó de tocar, las bestias se alejaron de él. Muchas veces, con el calor del mediodía, Orfeo pudo ver cerca de él al rey de las hadas que, junto con su séquito, vino a cazar por los alrededores acompañado por un griterío y un sonido de cuernos que apenas se escuchaba y también por los ladridos de los perros de caza. Sin embargo, ni el rey ni su séquito se llevaron jamás presa alguna, y tampoco nunca supo Orfeo adónde se fueron todos después. Y en otra ocasión, Orfeo pudo ver pasar junto a él lo que parecía ser un gran ejército bien pertrechado formado por mil caballeros de apariencia recia y feroz que estaban armados adecuadamente y habían desplegado sus estandartes. Estos sostenían en las manos, además, sus espadas desenvainadas. Y de igual manera, tampoco nunca supo Orfeo adónde se fueron. Y hubo una vez en la que este vio algo diferente. Vio a damas y caballeros vestidos con elegancia bailar con destreza mientras daban pasos gráciles de aquí para allá acompañados de tambores y trompetas y toda suerte de trovas.

Y cierto día vio cerca de él a sesenta damas montadas a caballo que parecían ser tan nobles y vivarachas como las avecillas que suelen posarse en las ramas. No había entre ellas ni un solo hombre. Y cada una de ellas sostenía en la mano un halcón mientras cabalgaban junto al río en busca de una presa. Y lograron muchas, por cierto, repartidas entre ánades reales, garzas y cormoranes. Los halcones fijaron muy bien su vista en las aves que salieron volando del agua, y no hubo uno solo de ellos que no atrapase y matase a la presa escogida, lo que hizo reír enormemente a Orfeo y decir:

- ¡A fe mía, qué hermosa cacería! En nombre de Dios, me voy a verla más de cerca. Yo solía asistir antaño a este tipo de cacerías con halcón.

Entonces, se levantó y hasta allí se aproximó. $\mathrm{Y}$ al contemplar detenidamente a una de las 
damas a la que se había acercado, se dio cuenta, sin ninguna duda, de que se trataba de su propia reina, la Dama Eurídice. Ambos se miraron mutuamente con gran interés, pero ninguno de los dos dijo nada. Las lágrimas brotaron de los ojos de Eurídice al percibir esta la tristeza que había en Orfeo, él, que en el pasado había sido tan majestuoso y había tenido tanto señorío. Cuando las otras damas notaron lo que estaba ocurriendo, instaron a Eurídice a ponerse en camino de nuevo. Eurídice ya no podía quedarse más tiempo con Orfeo.

- ¡Ay!, dijo aquel, - ¡cuánto dolor siento ahora! Muerte, ¿por qué no pones ya fin a mi vida? ¡Ay, mísero de mí, que no muero después de ver a Eurídice! ¡Ay! ¿De qué me sirve seguir viviendo si tanto mi esposa como yo somos incapaces de hablar el uno con el otro? ¡Ay, Dios! ¡Y que aún no me haya muerto! ¡A fe mía! Continuó diciendo, - que pase lo que pase, pero por donde sea que cabalguen estas damas, por allí encaminaré mis pasos sin demora sin importarme si viva o muera.

En seguida se puso la túnica del peregrino y se colgó el arpa en la espalda, y con buen ánimo se dispuso a marcharse sin esquivar obstáculo alguno en su camino. Las damas cabalgan hacia el interior de una roca y él detrás, sin detenerse ni un ápice. Cuando, ya en el interior de la roca, Orfeo hubo recorrido varias leguas, llegó a un bello país tan resplandeciente como un día soleado de verano, liso y plano y todo revestido de verde, y donde no parecían verse ni cerros ni valles. En mitad de la tierra observó un majestuoso y regio castillo de una altura portentosa. Toda su muralla exterior resultaba tan transparente y fulgurante como el cristal. Alrededor del castillo se erigían cien torres asombrosas y provistas de sólidas almenas. Los contrafuertes que sobresalían del foso formaban espléndidamente un arco de oro rojo. Las bóvedas estaban adornadas por completo con toda clase de esmaltes. En su interior había varias moradas espaciosas completamente decoradas con piedras preciosas. Incluso la columna menos bella que pudiera contemplarse estaba hecha por entero de oro bruñido.

Toda aquella tierra estaba siempre iluminada, pues cuando debía permanecer en la oscuridad y de noche, la luz de las piedras preciosas la hacía resplandecer con tanto esplendor como el sol al mediodía. Resulta imposible de describir, y mucho menos de imaginar, la obra tan exquisita que allí se había creado. Por todo ello, Orfeo piensa que se halla en la altiva corte del Paraíso. En este castillo se detuvieron las damas y se bajaron de sus cabalgaduras. Orfeo, a menos que hallase impedimento alguno, quiso entrar en él, de modo que golpeó la puerta del castillo, y el portero que allí se encontraba le preguntó qué es lo que deseaba.

- ¡A fe mía!, dijo Orfeo - ¡miradme bien, soy un trovador! He venido, si le place a vuestro señor, a entretenerlo con mis trovas.

El portero abrió en seguida la puerta y le dejó entrar en el castillo. Entonces, Orfeo comenzó 
a mirar a su alrededor, y vio tumbadas en el interior del recinto a personas que habían sido traídas hasta allí que parecían muertas pero que, en realidad, no lo estaban. Algunas no tenían cabeza; otras carecían de brazos; otras estaban cubiertas de heridas por todo el cuerpo; otras, que estaban atadas, habían perdido el juicio; las había también que estaban armadas encima de un caballo; otras que se habían atragantado al comer; otras que se habían ahogado en el agua; y otras que el fuego había consumido. También había en ese mismo lugar mujeres que estaban acostadas en una cama, algunas de ellas estaban muertas y otras se habían vuelto locas, y causaba asombro ver cómo había muchas entre ellas que estaban acostadas juntas como si estuvieran durmiendo la siesta. Todas ellas habían sido raptadas y traídas a este mundo por arte de magia y encantamiento. $Y$ allí mismo vio Orfeo a su propia esposa, a la Dama Eurídice, razón y objeto de su vida entera, que dormía bajo un manzano, y a la que había reconocido por su vestimenta. $Y$ tras contemplar todos estos portentos, entró en el salón de rey donde se encontró con una bella escena. Allí había un hermoso y resplandeciente dosel en cuyo interior estaban sentados su rey y su bella y dulce reina. Tanto resplandecían sus coronas y sus ropajes que apenas pudo Orfeo verlos bien. Y cuando terminó de observar todo aquello, este se postró de rodillas ante el rey y le dijo:

- Oh, señor, si fuera vuestra voluntad, os haría escuchar mi música.

El rey respondió:

- ¿Qué clase de hombre sois que hasta aquí habéis podido llegar? Ni yo ni nadie de los que están conmigo os hemos mandado llamar nunca. Desde que comencé a reinar en este mundo, nunca antes me había topado con alguien que hubiese sido tan insensato como para venir hasta nosotros, a menos, claro está, que yo hubiera querido hacerlo llamar.

- Señor, dijo Orfeo, - sabed ante todo que tan solo soy un pobre trovador, y que es costumbre nuestra entrar en las casas de los señores con el objeto de ofrecer nuestras trovas, incluso aunque no seamos bienvenidos.

Y sentándose ante el rey, Orfeo tomó su arpa, aquella de la que brotaban canciones tan alegres. Pero antes, vedlo afinarla como sólo él sabe hacerlo. Después, comenzó a tocar tan divinamente, que todos aquellos que en el palacio se hallaban, juzgando su música dulcísima, se acercan $^{1}$ a él para escucharlo recostándose a sus pies. El rey, que permanece sentado, escucha en silencio las trovas de Orfeo con interés.

\footnotetext{
${ }^{1}$ De nuevo el poeta pasa del tiempo pasado al tiempo presente como recurso narrativo de los poemas o de las canciones que se recitan o cantan oralmente; recurso que pretende dinamizar el ritmo del poema y acercar al lector al momento en que ocurren los acontecimientos para que los sienta y "vea" más de cerca.
} 
De hecho, tanto él como la majestuosa reina disfrutaron bastante con ellas. Entonces, cuando Orfeo terminó de tocar el arpa, le dijo el rey:

- Trovador, me gustan mucho vuestras trovas. Ahora pedidme lo que queráis, pues habré de pagaros pródigamente. Vamos, hablad si queréis comprobarlo.

- Señor, habló Orfeo, - os ruego que me concedáis aquella dama de aspecto resplandeciente que está allí durmiendo bajo el manzano.

- ¡No!, replicó el rey, - ¡eso jamás! Haríais una mala pareja, pues vos sois enjuto, de aspecto desaliñado y sucio, y ella, en cambio, es hermosa y no tiene mácula alguna, por lo tanto, sería algo abominable vedla en compañía vuestra.

- ¡Oh, señor!, - protestó Orfeo, - pero sería algo mucho más deshonroso escuchar una mentira de vuestros labios, noble rey. De modo que, señor, tal como acabáis de decir, cumplid con vuestra palabra sin reparo y concededme lo que os he pedido.

A lo que el rey respondió:

- Dado que tenéis razón en lo que decís, coged a la mujer de la mano y marchaos. Espero que seáis feliz con ella.

$\mathrm{Al}$ escuchar esto, Orfeo se arrodilló ante el rey y le dio las gracias sin demora. Cogió a su esposa de la mano y se dispuso a partir rápidamente de aquella tierra, de aquel país, tomando el mismo camino por el que vino. $\mathrm{Y}$ a pesar de que el trayecto fue muy largo llegó, por fin, a su propia ciudad, a Winchester, mas nadie supo que él era el rey. Y porque no quiso ser reconocido por nadie, no salió de los límites de la ciudad, sino que tanto él, disfrazado como un trovador de vida pobre, como su propia esposa, se alojaron con un mendigo en su cabaña, que era muy pequeña, y en ella Orfeo le pidió al mendigo que le diera algunas noticias de aquel reino y quién era el que lo gobernaba. El mendigo le puso al tanto de todo, de cómo la reina había sido arrebatada hace diez años por arte de magia y encantamiento; de cómo el rey se había exiliado sin que nadie supiera en qué país; de cómo el mayordomo real se había ocupado desde entonces de gobernar el reino; y de muchos otros asuntos. Al día siguiente, hacia el mediodía, tras hacer que su esposa se quedase con el mendigo en la cabaña, Orfeo tomó prestadas las ropas del mendigo a toda prisa, se colgó el arpa en la espalda, y se adentró en aquella ciudad para que todos pudieran verlo. Condes y barones aguerridos, ciudadanos y damas comenzaron a fijarse en él.

- ¡Mirad a ese hombre!, dijeron, - ¡qué largo tiene el cabello! ¡Mirad cómo le llega la barba hasta las rodillas! Camina como un árbol seco y torcido.

Y mientras iba caminando por la calle, al ver a su mayordomo real, Orfeo le llamó dándole un grito:

- ¡Señor mayordomo! ¡Por caridad! Soy un arpista de tierras paganas. ¡Ayudadme, pues estoy en apuros!

A lo que el mayordomo real respondió: 
- ¡Venid, venid conmigo! Lo que tengo, lo compartiré con vos. Por amor a mi señor, el caballero Orfeo, me complace recibir a todos los buenos arpistas.

En el castillo el mayordomo real se sentó a la misma mesa en compañía de muchos señores. Cerca de ellos había trompetistas y tamborileros, una buena cantidad de arpistas y músicos que ejecutaban la rota. Todos ellos tocaban sus instrumentos sin cesar. Mientras tanto, Orfeo permaneció en el comedor escuchándolos en silencio, y cuando terminaron de tocar, aquel cogió su arpa y comenzó a afinarla en alto. Después, tocó en el arpa las notas más hermosas que jamás se habían escuchado allí, haciendo las delicias de todos por igual. Al prestar más atención, el mayordomo real reconoció el arpa en seguida.

- Trovador, dijo, - si deseáis ver cambiada vuestra suerte, os ruego que me digáis dónde y cómo conseguisteis el arpa que tenéis con vos.

- Señor, - respondió Orfeo, - mientras viajaba por un lugar desolado y salvaje en una tierra desconocida, hallé en un valle a un hombre hecho pedazos que había sido devorado por leones y lobos de afilados dientes. Junto a él hallé esta misma arpa hace ahora diez años por lo menos.

- ¡Ay, qué desgracia! - exclamó el mayordomo real, - ese hombre era mi señor, el caballero Orfeo. ¡Ay, mísero de mí! ¿Qué haré ahora que he perdido a tan gran señor? ¡Ay de mí! ¡Maldito el día en que nací! ¡Qué amarga fortuna le fue concedida y qué muerte tan infame le fue destinada!

Y al proferir tales palabras, cayó al suelo desmayado. Sus barones trataron de incorporarlo en ese momento mientras le decían que esas cosas pasan en el mundo y que "no existe solución alguna contra la muerte." Entonces, fue en aquel instante cuando el rey Orfeo supo que su mayordomo real era un hombre leal al que debía amar como merecía, de modo que se puso en pie y dijo así:

- Mayordomo, prestad atención a lo que os voy a decir. Si yo fuera el rey Orfeo y hubiera padecido hace mucho tiempo en una región desolada y salvaje enormes penurias y calamidades, $y$ hubiera rescatado a mi reina, gentil dama, del país de las hadas ${ }^{1}$, y la hubiera traído hasta los mismos límites de la ciudad, y la hubiera dejado en la cabaña de un mendigo, y yo mismo hubiera venido hasta aquí a vuestro encuentro disfrazado con las ropas de un mendigo a fin de comprobar vuestra buena voluntad, y os hubiera hallado de este modo leal, entonces eso es algo que nunca tendríais que lamentar, y en verdad, quisierais o no, tendríais que convertiros en rey después de mí. Sin embargo, si os hubieseis alegrado de mi muerte, hubieseis sido desterrado al instante.

Entonces todos aquellos que estaban sentados en el interior del castillo se percataron de que

${ }^{1} \mathrm{O}$ del Otro Mundo. 
se trataba del rey Orfeo. El mayordomo real también se dio cuenta de ello perfectamente y se arrojó a los pies de Orfeo haciendo volcar la mesa en su agitación. También se arrodillaron todos los señores que allí se hallaban mientras gritaban al mismo tiempo:

- ¡Vos sois nuestro señor y nuestro rey!

Todos se alegraron de que Orfeo estuviese vivo. Luego lo condujeron de inmediato a su aposento y lo bañaron y afeitaron, y lo vistieron como un rey en toda su majestad y después, con gran solemnidad, trajeron a la reina a la ciudad entre música y canciones. ¡Oh, señor! Cuánta música se escuchó entonces y cuánto lloraron de alegría quienes vieron a Orfeo y a Eurídice regresar a la ciudad sanos y salvos. Ahora ved al rey Orfeo y a su dama Eurídice ser coronados de nuevo rey y reina. Muchos años vivieron después, y a la muerte de ambos, el mayordomo real se convirtió en rey. Y después de ello, los arpistas de Bretaña, que habían oído hablar de este suceso singular desde sus comienzos, compusieron un lay para delicia de todos, y le pusieron como título el nombre del rey. Así pues, el lay al que nos referimos, que es digno de escucharse por sus dulces notas musicales, se llama "Orfeo". Y así es cómo el rey Orfeo volvió a recuperar su felicidad. ¡Que Dios nos libre de todo mal! Amén. ${ }^{1}$

\section{References}

Laskaya, A., \& Salisbury, E. (Eds.). The Middle English Breton Lays. Teams Middle English Texts Series. Retrieved from: https://d.lib.rochester. edu/teams/text/laskaya-and-salisbury-middleenglish-breton-lays-sir-orfeo-introduction (date of acess: 15.09.2019)

Zipes, J. (2000). The Oxford companion to fairytales. Oxford: Oxford University Press.

${ }^{1} \mathrm{O}$ del Otro Mundo.El enlace al poema en inglés medio (Middle English) del “Caballero Orfeo" es el siguiente: [Laskaya, Salisbury]: https://d.lib.rochester.edu/teams/text/laskaya-and-salisbury-middle-english-breton-lays-sir-orfeo-introduction. (From The Middle English Breton Lays.1995). 


\section{TRANSLATION OF “SIR ORFEO” INTO SPANISH}

José Antonio Alonso Navarro, Professor of Modern Languages and Humanities, Norte University (Asuncion, Paraguay); e-mail: meildeja@yahoo.com.

bstract. Here we present a translation into Spanish of the medieval English poem titled "Sir

A Orfeo", which was composed in the late 13th or early 14th centuries within the WestminsterMiddlesex area. Our main spur has been to disseminate it amongst the modern Spanish-speaking readers due to its literary beauty and its story, a story which is not certainly innovative; however, it is innovative as to the way its author has succeeded in adapting the classical or Ancient Greek myth to the medieval English mindset of the readers or listeners of the time so as to arouse their interest, entertain them and teach them with a didactic purpose. The poem comprises all the elements inherent to a prototypical lay (or lai): a knight-king, a love story, a physical and spiritual quest, the otherworld (or fairyland), and moral and spiritual values which should be taken into account by the audience. We have attempted to make the translation of "Sir Orfeo" into Spanish as faithful as possible regarding the original English poem in order to maintain its literary essence, freshness and character. "Sir Orfeo" was a very popular poem in its time, and there is no doubt that it will become popular again in the $21^{\text {st }}$ century in the light of different perceptions and approaches.

Keywords: "Sir Orfeo", Orpheus, lay (or lai), Greek mythology, Celtic mythology, otherworld.

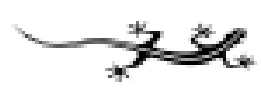

